\title{
The Study of Hope and Self-Efficacy in Hemodialysis Patients
}

Noghani. $\mathrm{F}^{1}$

Ghadirian. $F^{2}$

Sharifnia. $\mathrm{SH}^{3}$

${ }^{*}$ Fereydooni Sarijjeh. P4

1- Ph.D. Psychiatric Nursing, Associate Professor, Psychiatric Nursing Department, Faculty of Nursing and Midwifery, Tehran University of Medical Sciences, Tehran, Iran.

2- Ph.D. Psychiatric Nursing, Assistant Professor, Psychiatric Nursing Department, Faculty of Nursing and Midwifery, Tehran University of Medical Sciences, Tehran, Iran

3- Ph.D. Nursing Assistant Professor, Internal Surgery Department, Faculty of Nursing and Midwifery, Mazandaran University of Medical Sciences, Mazandaran, Iran.

4- ( ${ }^{*}$ Corresponding Author) MSc Student of Psychiatric Nursing, Faculty of Nursing and Midwifery, Tehran University of Medical Sciences, Tehran, Iran. Email: peimanfereidounisa@ yahoo.com

\section{Abstract}

Introduction: Loss of life meaning, hopelessness and pessimism, can be the cause of many problems dialysis patients facing.

Objective: Considering the importance of self-efficacy role in self-care, this study aimed to investigate the hope and self-efficacy of hemodialysis patients.

Material and Methods: The present study is a descriptive-analytical study performed on 100 patients. Demographic questionnaires, Snyder Hope Questionnaire and Sherer Self-efficacy Questionnaire were used in this study. After data collection, the data were analyzed by SPSS 23. Significance was considered 0.05

Results: In this study, 52 males and 48 females were included. The mean and standard deviation of age were 51 and 9.51 , respectively; $17 \%$ of them were single and $81 \%$ were married and $2 \%$ were widowed. The results showed that the mean score and standard deviation of hope for patients were 37.84 and 0.73 , and of selfefficacy were 50.76 and 2.76, respectively. Given that the low score on the Snyder Hope tool indicates lower hope, of the score of hope in = hemodialysis patients was considered low and the self-efficacy score was moderate. There was a significant relationship between self-efficacy and patients' hope, ie, self-efficacy increases as hope increases $(\mathrm{P}=0.00)$.

Discussion and Conclusion: Based on results of this study, patients undergoing hemodialysis have a low mean score of self-efficacy and low hope, so the researchers propose strategies for accurate and holistic evaluation of these patients by nurses.

Keywords: Hemodialysis, Hope, Patients, Self-Efficacy. 


\section{بررسى ارتباط بين اميد و خودكار آمدى بيماران تحت همودياليز}

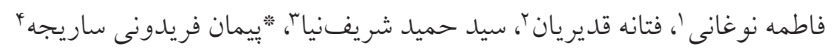

جكيده

مقدمه: نداشتن معنا در زندكى و نا اميدى و نداشتن لذت مثبت مىتواند عامل بسيارى از معضلات و مشكلات بيماران

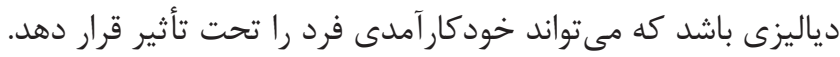
هدف: با توجه به اهميت نقش خودكار آمدى بيماران در امر مراقبت از خود، اين مطالعه با هدف بررسى ارتبات ارتباط بين اميد و خودكارآمدى بيماران تحت همودياليز انجام كرفت.

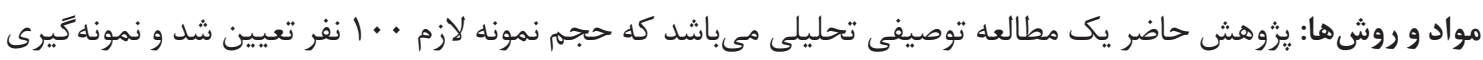

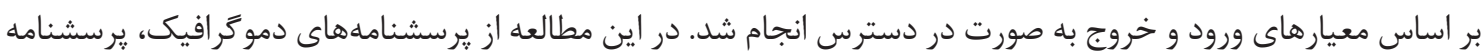

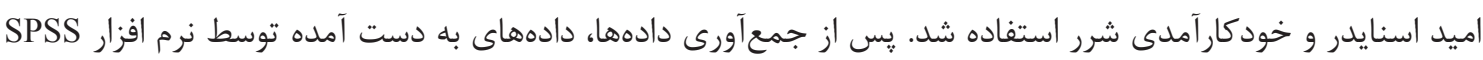

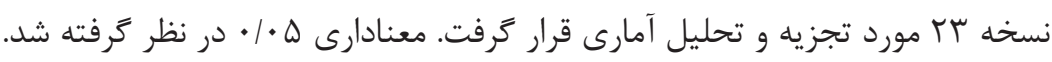

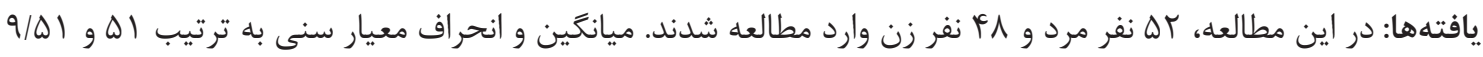

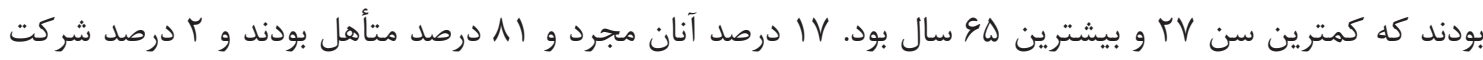

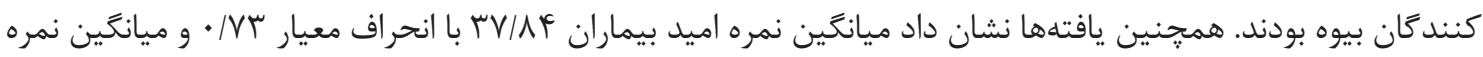

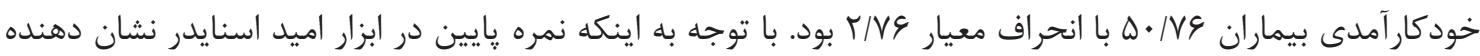

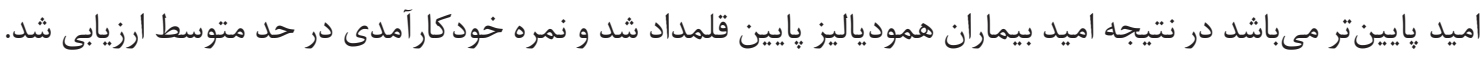

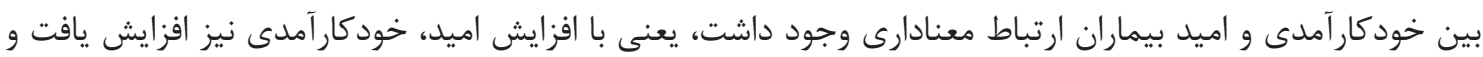

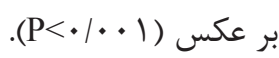

بحث و نتيجهَيرى: بر اساس يافتههاى اين مطالعه، بيماران تحت همودياليز از ميانكين نمره خودكارآمدى و اميد پإيين برخوردار هستند، بدين ترتيب يزوهشكران طراحى راهبردهايى را براى ارزيابى دقيق و كل گراى اين گروه از بيماران را توسط يُرستاران بيشنهاد مى كنند.

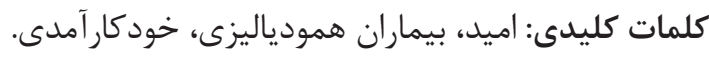

\begin{tabular}{|c|c|c|}
\hline $1 \mu 9 \wedge / 1 / 10$ & ت ت اريخ دريافت: ت & 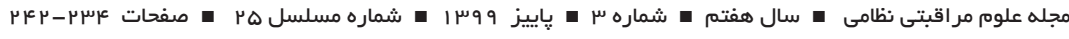 \\
\hline І & تاريخ يذيرش: ت & \\
\hline Іщя१/१/щ。 & 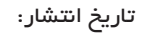 & \\
\hline
\end{tabular}

مىشود به همين دليل توجه كشور هاى ييشرفته را به خود معطوف مقدمه

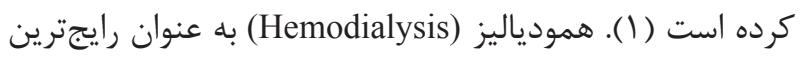
بيمارى مزمن كليوى از جمله مشكلات سلامتى در دنياى امروز روش جايكزين درمان Replacement Therapy) اين بيمارى هستند كه موقعيت تهديدكنندهاى براى وضعيت سلامتى، مشكلات كوناكونى در ابعاد مختلف زندكى بيماران ايجاد مى كند روند اقتصادى و اجتماعى فرد مبتلا، خانواده و جامعه او محسوب 
از دو عنصر تشكيل شده است، عنصر عاملى و عنصر راهبردى.

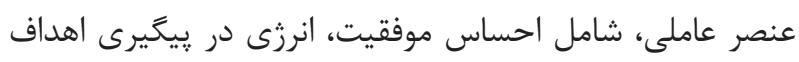

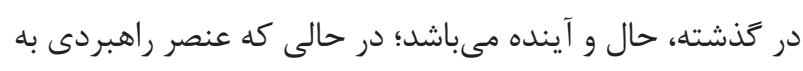

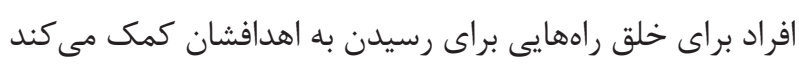

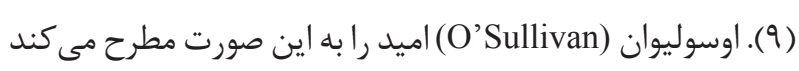

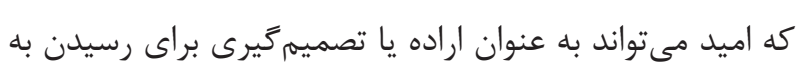

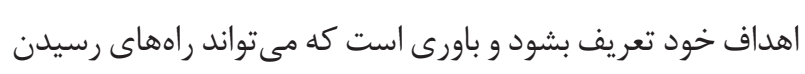
به آن اهداف را ي ييدا كند (•) (1).

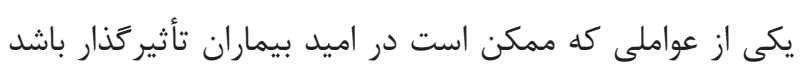

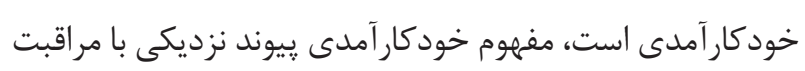

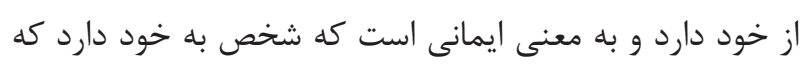

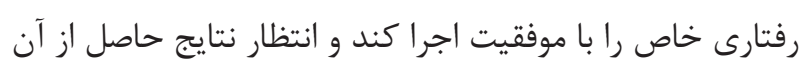

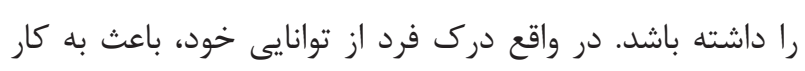

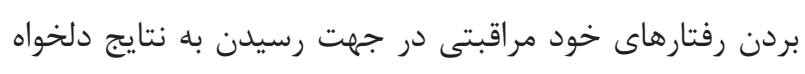

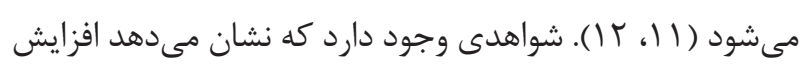
خود كارآمدى بيماران دياليزى با بهبود كنترل وزن بين جلسات

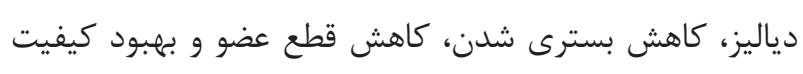

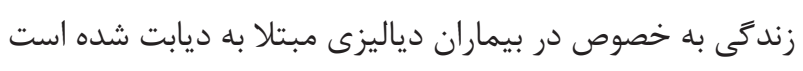

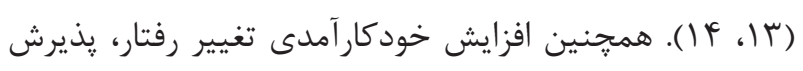
درمان و در نتيجه ارتقاء سلامت جسمى و روانى را به همراه داشته أنه

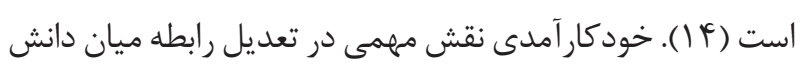

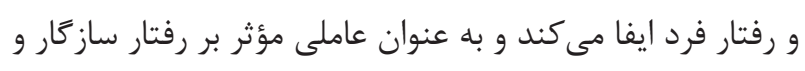

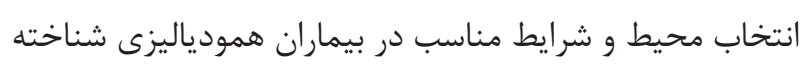

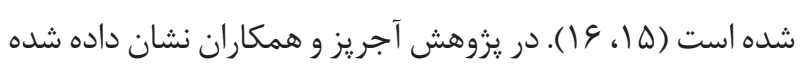

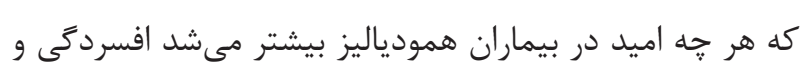

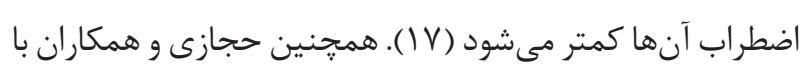
بررسى اميد در مراقبت كنند أنان و بيماران همودياليزى دريافتند كه سطوح اميد در بين شركت كنند كان هر دو كروه يايين بود (1) (1).

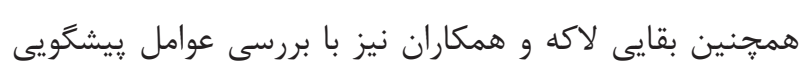
كننده خودكارآمدى در بيماران تحت همودياليز دريافتند كه هـ خودكارآمدى ضعيف در بيماران تحت درمان با دياليز مشاهده

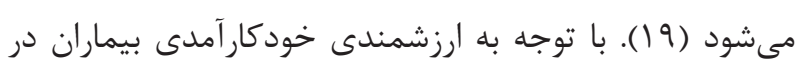

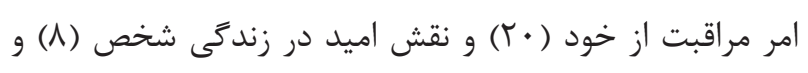

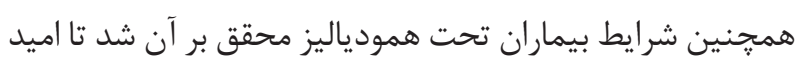

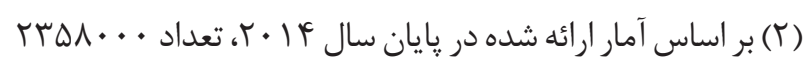

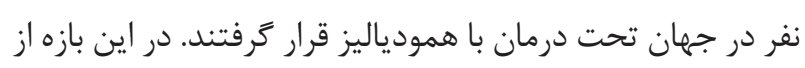
زمان وابستخى به همودياليز در استان هاى مختلف كشور در يايان

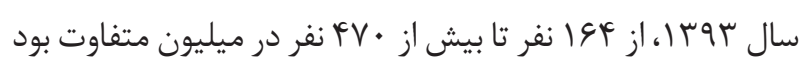

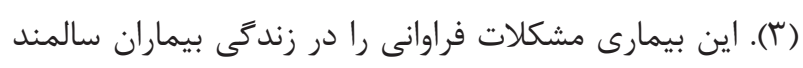

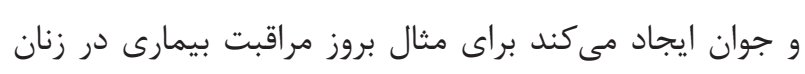

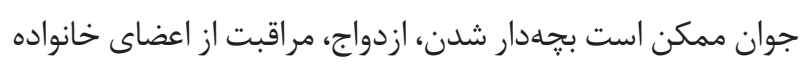

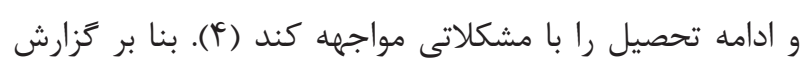

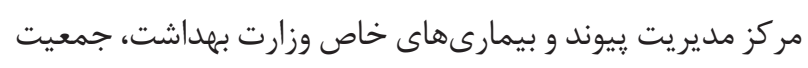

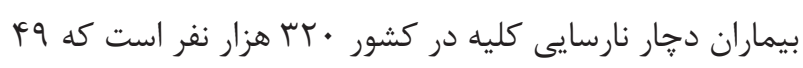

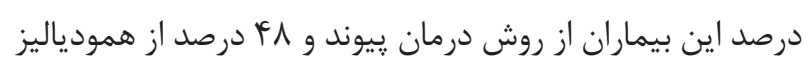

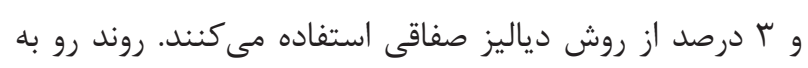

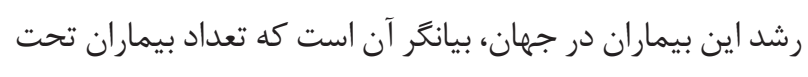
درمان هاى جايكزين، مثل ييوند كليه، دياليز صفاقى و همودياليز

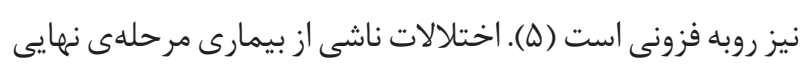

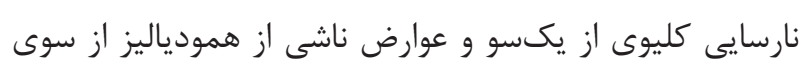

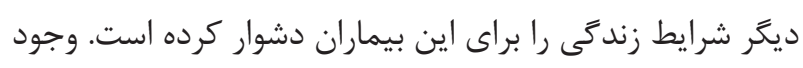

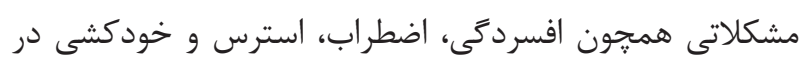

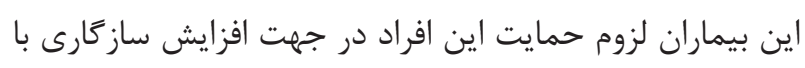
بيمارى را نشان مى دهد (9). بيماران تحت درمان با همودياليز به إنه

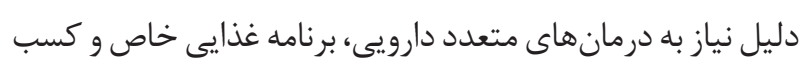

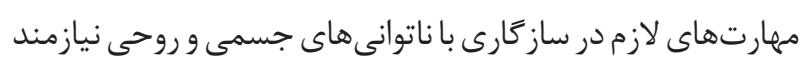
آموزش مخصوص و مداوم هستند (V). مطالعات نشان مى دمهند

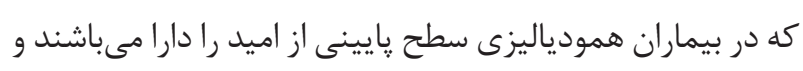

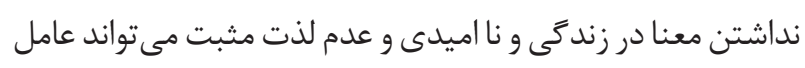

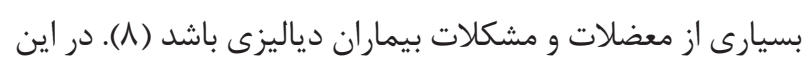

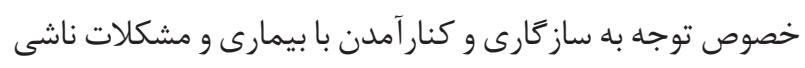

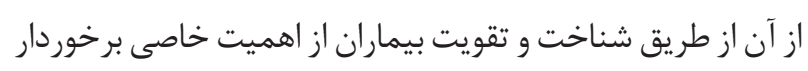

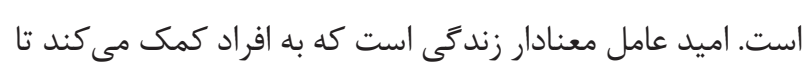

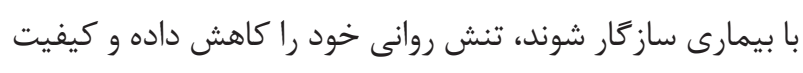

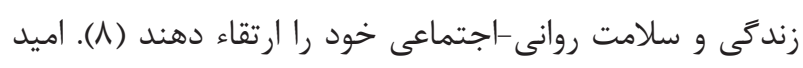

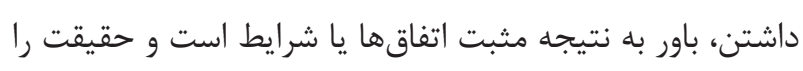
زنده نغَه مى دارد و سبب مى شود خلاقيت براى مقابله با مشكلات

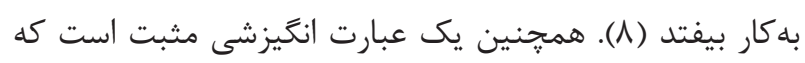


و تعداد دفعات همودياليز در هفته بود. روايى اين برسشنامه توسط ه نفر از اساتيد هيئت علمى تائيد شد. يرسشنامه خودكار آمدى شر ر:اين يرسشنامه توسط شرر و همكاران

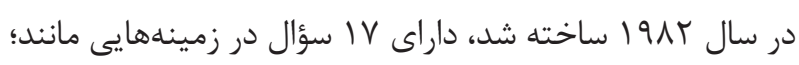

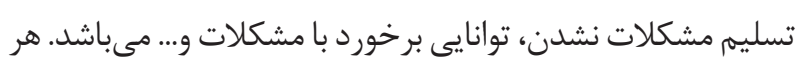

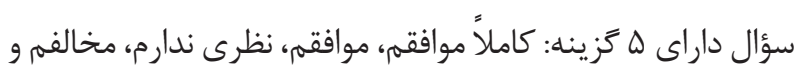
كاملاً مخالفم است. نمرهدهى به اين ترتيب است كه به به هر سؤال

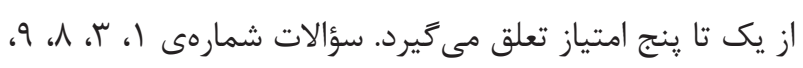

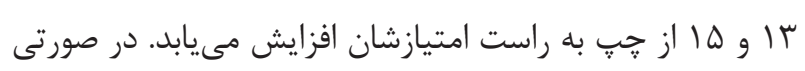

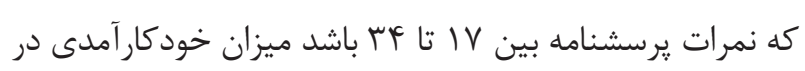

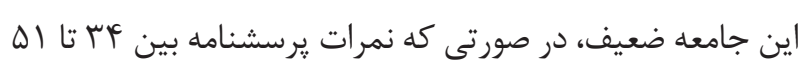

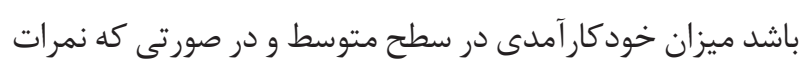

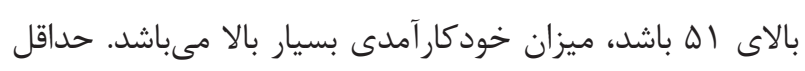

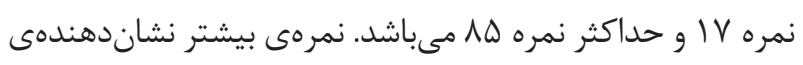

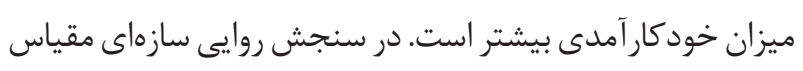

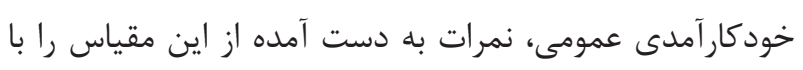

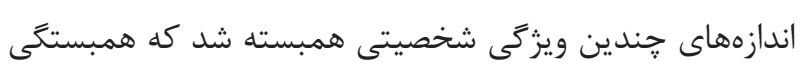

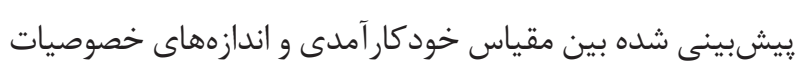

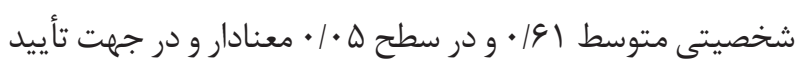

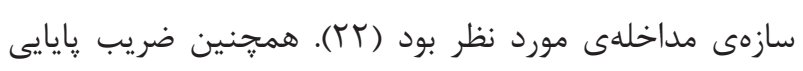

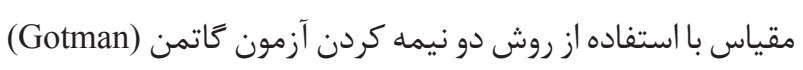

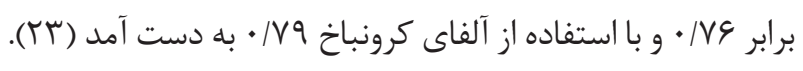

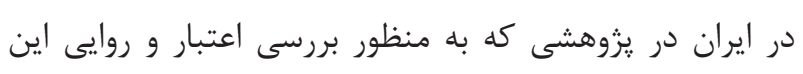

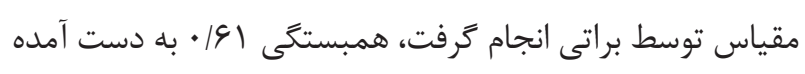

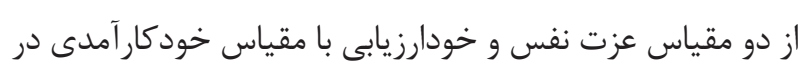

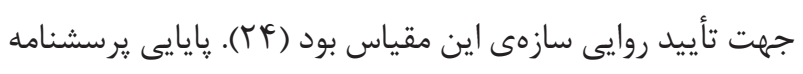

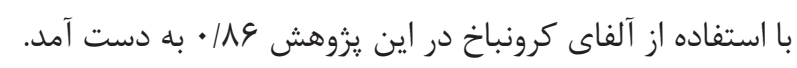
يرسشنامه اميد اسنايدر: مقياس اميد اسنايدر كه توسط اسنايدر و

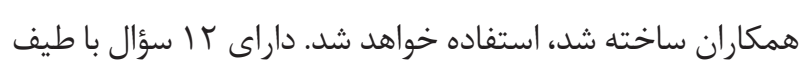

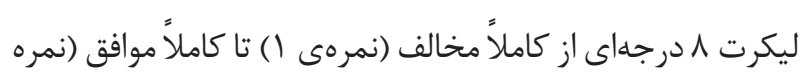

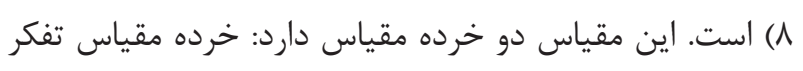

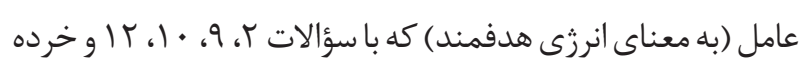
مقياس مسيرها (برنامهريزى براى رسيدن به اهداف) با سؤالات
و خود كار آمدى بيماران تحت همودياليز را مورد سنجش قرار دهد، پس از جستجوى كتابخانهاى، اينترنتى يزوهشى در خصود

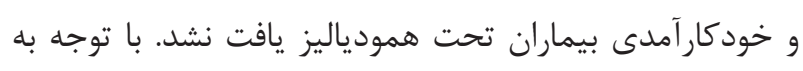

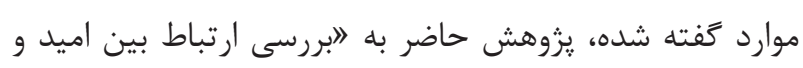

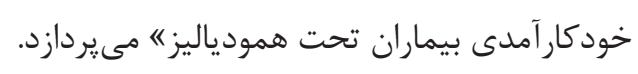

\section{مواد و روشها}

يزوهش حاضر يك مطالعه توصيفى تحليلى مىباشد. جامعه آمارى

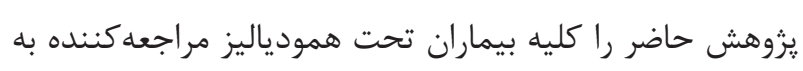

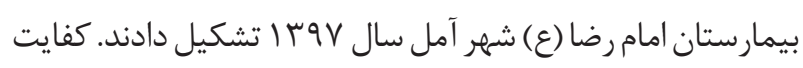
حجم نمونه به كمك نرمافزار G*Power بر اساس مطالعه مشابه

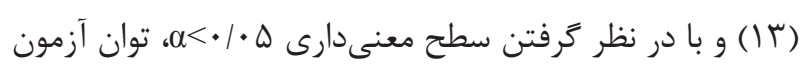

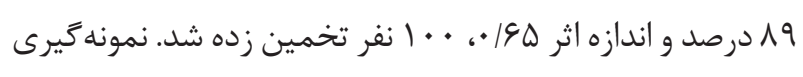
بر اساس معيارهاى ورود و خروج به صورت در دسترس انجام شد.

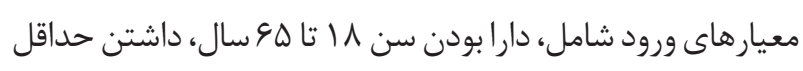

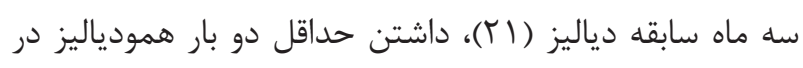

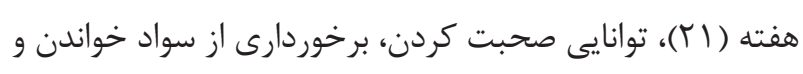
نوشتن، توانايى فارسى صحبت كردن، نداشتن مشكلات شناختى

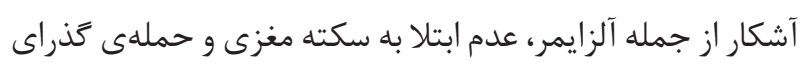

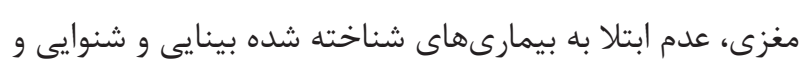

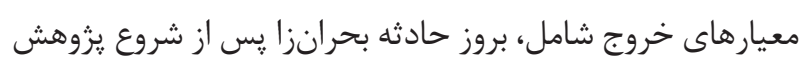

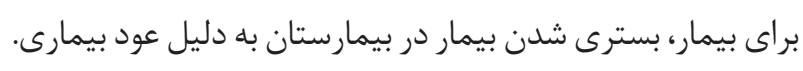

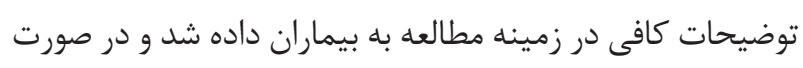

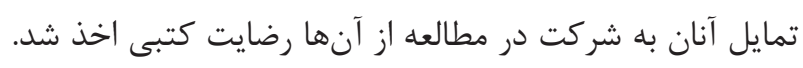

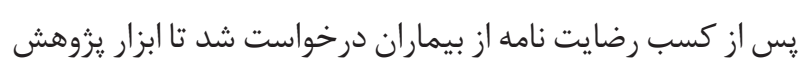

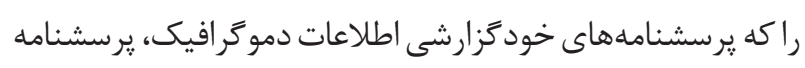

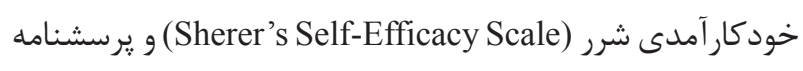

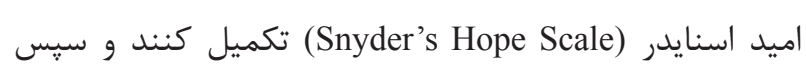

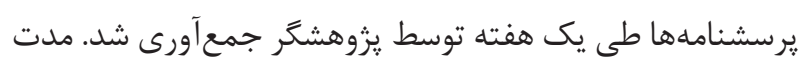

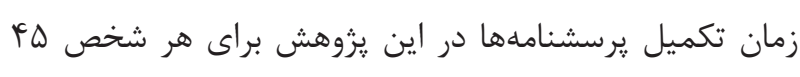
دقيقه بود.

يرسشنامه اطلاعات دموكرافيك: اين يرسشنامه براى سنجش برد

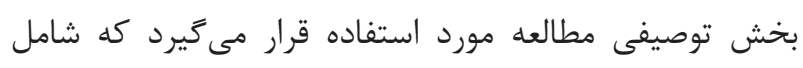
اطلاعاتى نظير سن، جنس، شغل و تحصيلات، سابقه همودياليز 
و انحراف معيار سنى به ترتيب الهو اله/9/ بودند كه كمترين سن

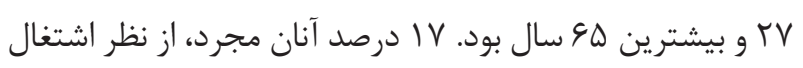

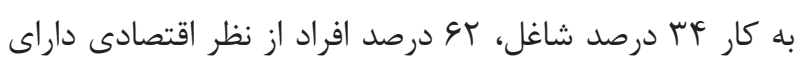

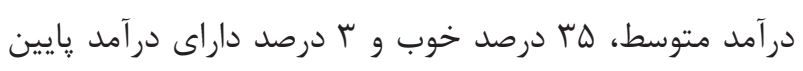

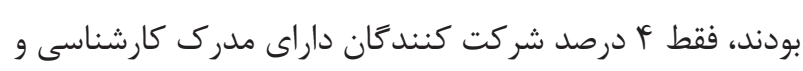

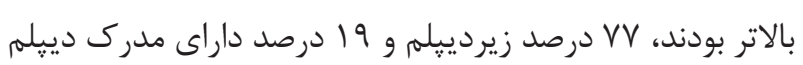

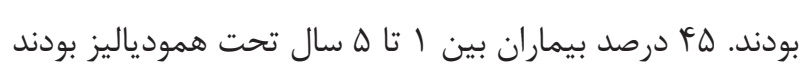

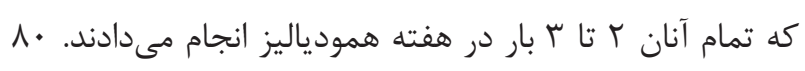
درصد بيماران از نظر مالى و 19 درصد از نظر عاطفى تحت حمان همايت خانواده خود بودند (جدول ()).

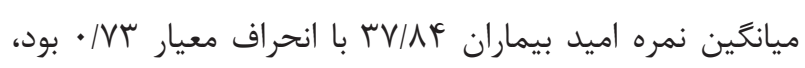

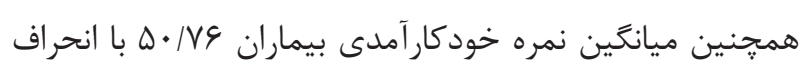

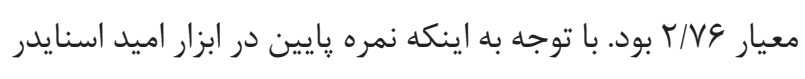

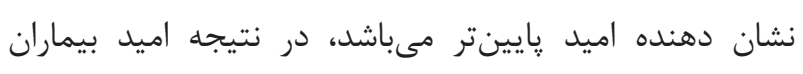

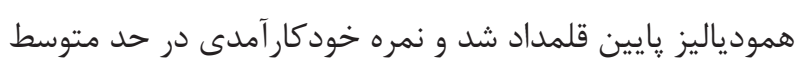

جدول ا - مشخصات دموكر افيك بيمار ان تحت مطالعه

\begin{tabular}{|c|c|c|}
\hline فراوانى (فراوانى نسبى) & & متغي \\
\hline $\operatorname{lV}(/ .1 \mathrm{~V})$ & مجرد & \\
\hline$\Lambda 1(/ . \Lambda 1)$ & متأهل & تأهل \\
\hline$r(/ . r)$ & بيوه & \\
\hline$M F^{L}(/ . M Y)$ & شاغل & \\
\hline $4 /(/ .41)$ & بيكار & - \\
\hline $19(\% 19)$ & بازنشسته & \\
\hline$r q(/ . T G)$ & خانهدار & \\
\hline ( & كمتر از يك سال & \multirow{4}{*}{ مدت ابتلا به بيمارى } \\
\hline$F \Delta(/ . F \Delta)$ & ا تا ه سال & \\
\hline $11(\% 11)$ & ع تا •ا سال & \\
\hline $\mathrm{V}(/ \mathrm{V})$ & || تا ها سال & \\
\hline$r(/ . \mu)$ & دوستان & \multirow{4}{*}{ حمايت مالى } \\
\hline $14(.14)$ & كميته امداد & \\
\hline$\Lambda \cdot(/ . \Lambda \cdot)$ & خانواده & \\
\hline$r(/ . \omega)$ & خيرين & \\
\hline$\Delta(/ . \Delta)$ & دوستان & \multirow{4}{*}{ حمايت عاطفى } \\
\hline$r(/ . r)$ & كميته امداد & \\
\hline$\wedge 9(/ . \wedge 9)$ & 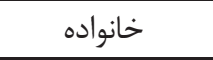 & \\
\hline$r(/ / r)$ & خيرين & \\
\hline
\end{tabular}

و 11 به عنوان سؤالات انحرافى از موضوع برسشنامه مىباشد و

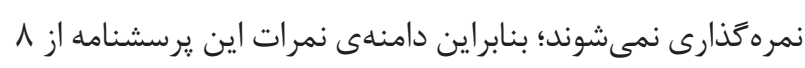

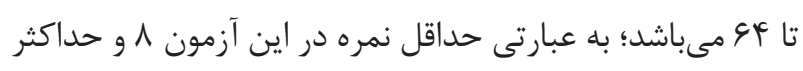

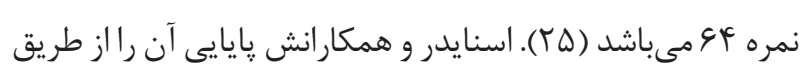

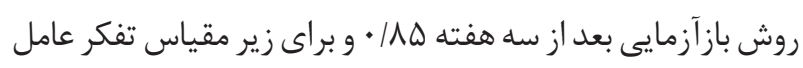

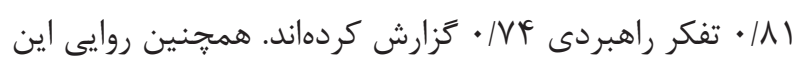

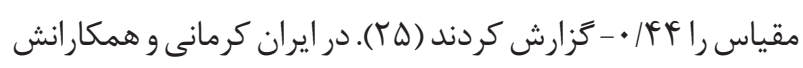

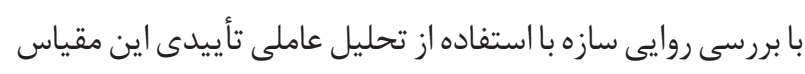

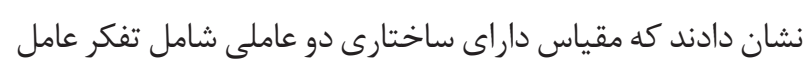

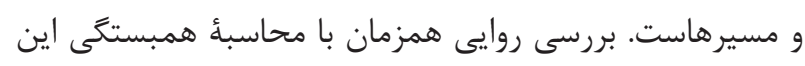

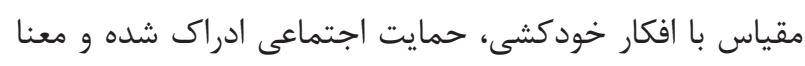
بيانكر رابطه منفى بين نمرات مقياس اميد با نمرات مقياس افكار

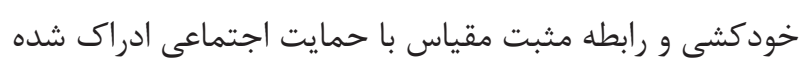

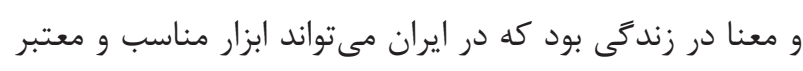
جهت استفاده باشد. همجنين ضريب زيايايى اين مقياس با استفاده

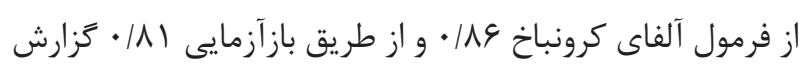

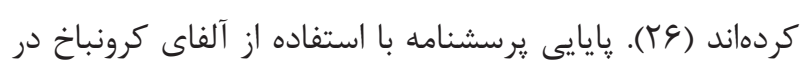

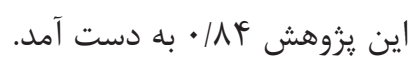

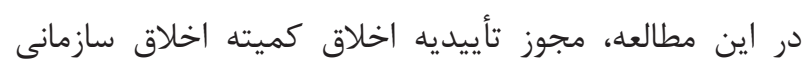
دانشكدهاى يرستارى و مامايى و توانبخشى دانشخاه علوم

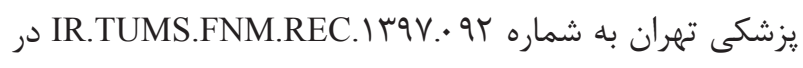

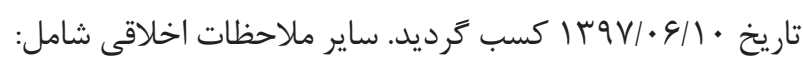

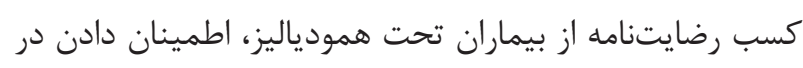

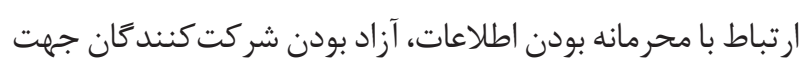

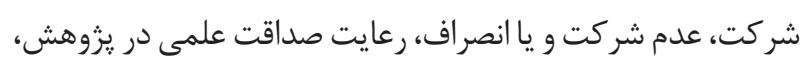

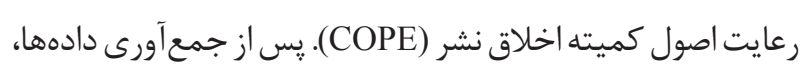

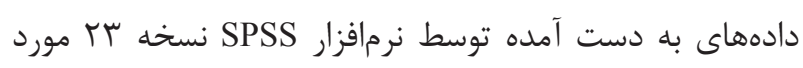
تجزيه و تحليل آمارى قرار ترفتند. جهت توصيف و تحليل دادهها، از آمار توصيفى نمايى كلى از توزيع و براكندگى متى متغيرها استفاده

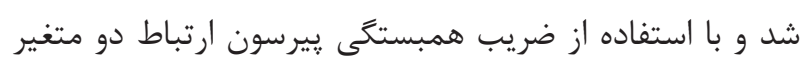
با هم و بنجيده اسفاده از صريب همبستى يِيرسون ارباط دو متعير

يافته ها

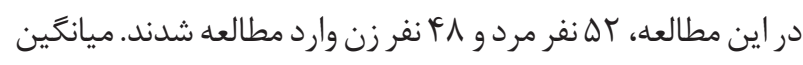


جدول r - ميانكَين و انحراف معيار نمره اميد و خودكار آمدى بيماران تحت همودياليز

\begin{tabular}{|c|c|c|c|c|}
\hline $\mathbf{P}$ & ضريب همبستخى & انحراف معيار & ميانغين & متغير \\
\hline$\cdot 1 \cdot \cdot$ & $\cdot / \Lambda$ & $\cdot / \mathrm{VH}$ & rV/AF & اميد \\
\hline & & T/VG & $\Delta \cdot / V \varphi$ & خود كار آمدى \\
\hline
\end{tabular}

بالا با انكيزه بالاتر و يافشارى بيشتر با موانع و مشكلات رو به رو شده و كارآيى بيشترى از خود نشان خواهد داد. افراد با خودكار آمدى

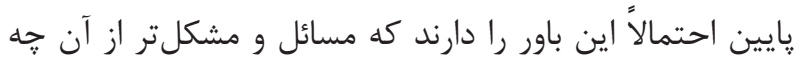
واقعاً هستند، مى باشند. باورهاى خود كار آمدى از جمله قوىترين عوامل پيشبينى كننده رفتار افراد است. باور به خودكارآمدى بر بسيارى از جنبههاى زندگى مانند گزينش اهداف، تصميمگيرى، ميزان تلاش، سطح استمرار، پايدارى و رويارويى با مسائل خالش برانخيز، سطح انخيزش، اجراى اهداف تأثير مى خذارد (عس-سع).

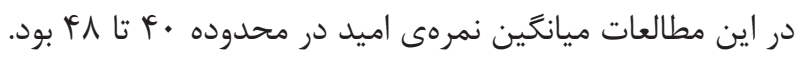
از آنجا كه عوامل متعددى بر اميد تأثيركذار است تفاوت جوامع

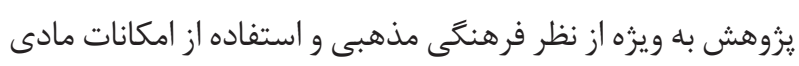
بيشتر مىتواند موجب اين تفاوتها باشد؛ و همجنين ويثز فردى نيز مىتواند از عوامل تأثير حذار باشد. خود كارآمدى نقش مركزى در فر آيندهاى انخيزشى و اكتسابات عملكرد فرد دارد و قضاوتهاى خودكارآمدى تعيين مىكنند كه فرد روى يك تكليف جقدر تلاش كرده و يافشارى خواهد كرد. فرد داراى خودكارآمدى قوى تلاش زيادى روى تكاليف جالشانگيز براى كسب موفقيت انجام خواهد داد. در حالى كه افراد با خودكارآمدى ضعيف تلاششان قابل توجه نبوده و يا بعد از شروع هر عملى دست از تلاش خواهند كشيد (هَ). شخص با خود كارآمدى بالا با انخيزه بالاتر و ڤافشارى بيشتر با موانع و مشكلات رو به رو شده و كارايى بيشترى از خود نشان خواهد داد.

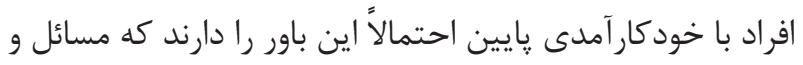

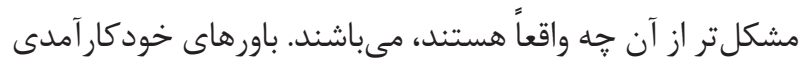
از جمله قوىترين عوامل ريشبينى كننده رفتار افراد است. باور به خودكارآمدى بر بسيارى از جنبههاى زندگى مانند ززينش اهداف، تصميمگيرى، ميزان تلاش، سطح استمرار، پايدارى و رويارويى با مسائل جالش برانگيز، سطح انخَزش، اجراى اهداف

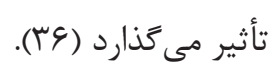

رو به يايين ارزيابى شد. همجنين بين خود كار آمدى و اميد بيماران ارتباط معنادارى وجود دارد، يعنى با افزايش اميد، خودكار آمدى

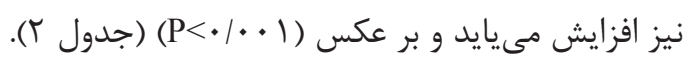

\section{بحث و نتيجه كيرى}

اين مطالعه با هدف تعيين ميزان اميد و خود كار آمدى بيماران تحت همودياليز در سال V V Y I انجام گرفت. با توجه به يافتههاى يزوهش

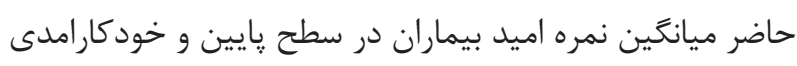
بيماران קايين قلمداد شد. در يزوهش فرنيا و همكاران (YV) ميانگين نمره اميد پايين بود، مطالعات خارجى نيز نشان دادند كه

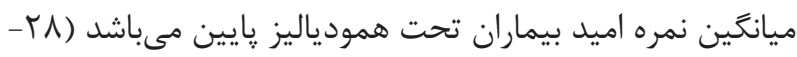
(ז) كه نتايج اين مطالعات هم راستا با يزوهش حاضر مىباشند. وجود اميد در بيمارىها امرى مههم است و در واقع به مبارزه طلبيدن در جهت غلبه بر محدوديتهاى زندگى و تلاش براى زندگى كردن است (rr). در يزوهش كمرى و همكاران (rT)، نتايج حاصل نشان داد كه قبل از مداخله نمره اميد بيماران در سطح يايين مىباشد. همجنين نتايج يزوهشى نشان داد كه نمرات اميد قبل از مشاوره در زروه مداخله و قبل و بعد در زروه كنترل

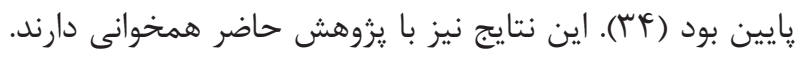
يروهش ديخرى كه تأثير معنويت را بر اميد سنجيد، يزوهش دهياشى و همكاران (N) بود، نتايج اين :ثروهش نيز با مطالعات

قبلى و يزوهش حاضر همخوانى دارد. خود كار آمدى نقش مركزى در فرآيندهاى انخيزشى و اكتسابات عملكرد فرد دارد و قضاوتهاى خود كارآمدى تعيين مى كنند كه مه فرد روى يك تكليف جقدر تلاش كرده و پافشارى خواهد كرد. فرد داراى خودكارآمدى قوى تلاش زيادى روى تكاليف جالش انخَيز براى كسب موفقيت انجام خواهد داد. در حالى كه افراد با خود كار آمدى ضعيف تلاششان قابل توجه نبوده و يا بعد از شروع هر

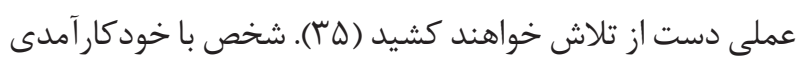


مبتلا به نارسايى كليوى بوده است و در صورت نياز و به تعميمم به ساير بيماران با احتياط و دانش كافى اين كار صورت بخيرد. اين يزوهش بر روى بيماران 11 تا هو سال انجام گرفته لذا، قابليت تعميم دهى به كل جامعه را ندارد. بر اساس يافتههاى اين مطالعه، بيماران تحت همودياليز از ميانگين نمره خود كار آمدى و اميد پايين برخوردار هستند، با توجه به اينكه بينه يرستاران سهمم بسيار زيادى در مراقبت و آموزش بيماران دارند.

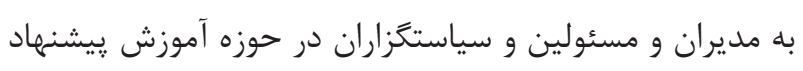
مىشود طراحى راهبردهايى را براى ارزيابى دقيق و كل گراى اين گروه از بيماران مد نظر قرار دهند.

تشكر و قدردانى

اين مقاله بركرفته از ياياننامه كارشناسى ارشد رشته روان يرستارى مىباشد كه در دانشعاه علوم يزشكى تهران در تاريخ

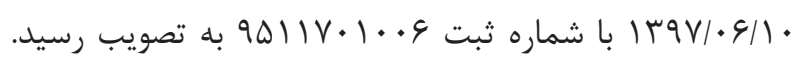
نويسند

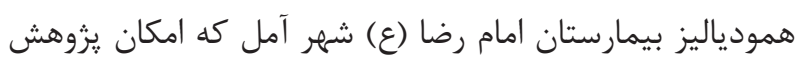
حاضر را فراهم ساختند كمال تشكر و قدردانى را دارند.

\section{تضاد منافع}

بدين وسيله كليه نويسند كان تصريح مىنمايند كه هيج كونه تضاد منافعى در خصوص مطالعه حاضر وجود ندارد.

\section{References}

1- Lederer E, Ouseph R. Chronic kidney disease. Am J Kidney Dis. 2007;49(1):162-71. DOI: 10.1053/j.ajkd.2006.09.021 PMID: 17185158

2- Jahromi M, Poorgholami F, Rahmanian F, Rahmanian E. Effects of Self-Care Education with Telephone Follow-up on Self-Efficacy level in Hemodialysis Patients. Biosciences, Biotechnology Res Asia. 2016;13(1):375-81. DOI: 10.13005/bbra/2043

3- Firoozjayi I, Adib-Hajbaghery M, Adib M. Frequency of nursing care of vascular access in hemodialysis patients. Med Surg Nurs J. 2016;5(3):6-11.

4- Molsted S, Prescott L, Heaf J, Eidemak I. Assessment and clinical aspects of health-related quality of life in dialysis patients and patients with chronic kidney disease. Nephron Clin Pract.
در يزوهش بقايى لاكه و همكاران (9 (1) ميانخين نمره خود كار آمدى ه/9 بود كه يايينتر از نمره ميانخَين يزروهش حاضر بود. همجنين در يزوهش ديخرى ميانگين نمره خودكارآمدى متوسط برآورد شد، لذا، خودكارآمدى به عنوان يكى از عوامل مؤثر در كنترل

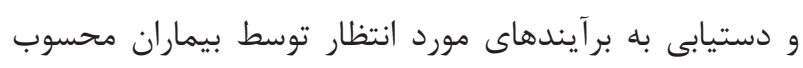
مىشود، بنابراين افزايش خودكارآمدى بيماران مىتواند سبب افزايش توان خودمراقبتى شود ( (f)). در مطالعه دهكرى و همكاران

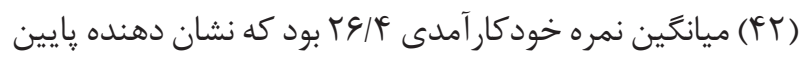
بودن نمره خود كار آمدى در بيماران همودياليز مىباشد و با نتايج مطالعه حاضر همخوانى دارد. نتايج يزوهشى نشان داد ميانگين

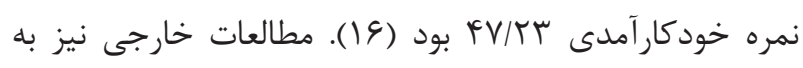
يايين بودن ميانكين نمره خود كارآمدى در بيماران همودياليزى تاكيد داشتهاند (T/F، FF) كه نتايج مطالعات همسو با مطالعه حاضر مىباشد. در زمينه خود كار آمدى مقالهاى كه ناهمسو با نتايج يثوهش باشد يافت نشد. با توجه به نتايج يزوهشهاى قبلى و مطالعه حاضر بهتر است كه مطالعات مداخلهاى در اين زمينه براى افزايش ميانخين نمره خود كارآمدى و اميد انجام گَيرد. در اين يزوهش از يرسشنامه استفاده كرديد، در نتيجه ممكن است برخى از افراد از ارائه ياسخ واقعى خوددارى كرده و ياسخ غيرواقعى داده باشند كه براى بررسىهاى بيشتر ييشنهاد مى گردد از مطالعات كارآزمايى بالينى كه يرسشنامهها دو بار توسط بيماران ير مىشود در آينده استفاده شود. همجنين نتايج يزوهش حاضر قابل تعميم به بيماران

2007;106(1):c24-33. DOI: 10.1159/000101481 PMID: 17409766

5- Glover C, Banks P, Carson A, Martin CR, Duffy T. Understanding and assessing the impact of end-stage renal disease on quality of life: a systematic review of the content validity of selfadministered instruments used to assess health-related quality of life in end-stage renal disease. Patient. 2011;4(1):19-30. DOI: 10.2165/11584650-000000000-00000 PMID: 21766891

6- Shahgholian N, Mardanian Dehkordi L. Spiritual Health in Patients undergoing Hemodialysis. Iran J Nurs. 2016;29(103):607. DOI: $10.29252 /$ ijn. 29.103 .60

7- Ebrahimi H, Sadeghi M, Amanpour F, Dadgari A. Influence of nutritional education on hemodialysis patients' knowledge and quality of life. Saudi J Kidney Dis Transpl. 2016;27(2):250-5. 
DOI: 10.4103/1319-2442.178253 PMID: 26997377

8- Dehbashi F, Sabzevari S, Tirgari B. The relationship between spiritual well-being and hope in Hemodialysis patients referring to the Khatam Anbiya hospital in Zahedan 2013-2014. MedEthics J. 2015;9(30):77-97.

9- Cheung Y. Psychological First Aid as a Public Health Disaster Response Preparedness Strategy for Responders in Critical Incidents and Disasters: The Chinese University of Hong Kong (Hong Kong); 2014.

10- O’Sullivan G. The Relationship Between Hope, Eustress, SelfEfficacy, and Life Satisfaction Among Undergraduates. Social Indicators Res. 2010;101(1):155-72. DOI: 10.1007/s11205-0109662-z

11- Fass M, Khoury-Kassabri M, Koot H. Associations between Arab Mothers' Self-Efficacy and Parenting Attitudes and their children's Externalizing and Internalizing Behaviors: Gender Differences and the Mediating Role of Corporal Punishment. Child Indicators Res. 2017;11(4):1369-87. DOI: 10.1007/s12187-017-9480-9

12- Gol H, Seighalani M, Rostami A, Asadbeigi A. Prediction of general self-efficacy of Allameh Tabatabaei University students based on their life quality. Europ Online J Natural Social Sci. 2013;2(4):489.

13- Aujoulat I, d'Hoore W, Deccache A. Patient empowerment in theory and practice: polysemy or cacophony? Patient Educ Couns. 2007;66(1):13-20. DOI: 10.1016/j.pec.2006.09.008 PMID: 17084059

14- Bandura A. Social Foundations of Thought \& Action: Englewood Cliffs, NJ; 1986.

15- Boroumand S, Shahriari M, Abbasi Jebeli M, Baghersad Z, Baradaranfard F, Ahmadpoori F. Determine the level of selfefficacy and its related factors in patients with ischemic heart disease: A descriptive correlational study. Iranian J Nurs Res. 2015;9(4):61-9.

16- Smaeli M, Alikhani M, Hosseini F. The quality of life and self-efficacy of the patients under hemodialysis. Iran J Nurs. 2005;18(41):77-84.

17- Mirbagher-Ajorpaz N, Aghajani M, Morsaee F, Zabolian Z. The Relationship between Hope and Depression-Anxiety in Patients Undergoing Hemodialysis. J Health \& Care. 2016;18(1):55-62.

18- Hejazi SS, Nikbakht S, Nasiri ZarrinGhabaee D, Akaberi A, Nazari Sheyhaki A. Hope in caregivers and hemodialysis patients. J North Khorasan Univ Med Sci. 2015;6(4):807-17. DOI: 10.29252/ jnkums.6.4.807

19- Baghaie-lakeh M, Bozorgzade M, Paryad E, Ehsan Kazemnejad L, Sefati A. Predictive Factors of Self-Efficacy in Patients Receiving Hemodialysis. J Health \& Care. 2016;18(2):101-10.

20- Ramezani M, Ahmadi F, Mohammadi E, Kazemnejad A. Spiritual care in nursing: a concept analysis. Int Nurs Rev. 2014;61(2):2119. DOI: 10.1111/inr.12099 PMID: 24712404

21- Oshvand K, Ghlyaf M, Homayounfar S. The effects of physical training during dialysis on the prevention of anemia in hemodialysis patients. Scientific Journal of Hamadan Nursing \&
Midwifery Faculty. 2015;23(4):65-76

22- Marzabadi A. Relationship between Physical-Mental Health and Spirituality with Self-Efficacy in Military Staff. Journal of Military Medicine. 2015;16(4):217-23.

23- Sherer M, Maddux J, Mercandante B, Prentice-Dunn S, Jacobs B, Rogers R. The Self-Efficacy Scale: Construction and Validation. Psychological Reports. 2016;51(2):663-71. DOI: 10.2466/ pr0.1982.51.2.663

24- Zare H, Mehmannavazan A. The effectiveness of encouragement training on promotion of general self-efficacy and resiliency of female-headed households. 2015;3(1):35-57.

25- Snyder CR, Ilardi SS, Cheavens J, Michael ST, Yamhure L, Sympson S. Cognitive Therapy and Research. 2000;24(6):747-62. DOI: $10.1023 / \mathrm{a}: 1005547730153$

26- Kermani Z, Khodapanahi M, Heidari M. Psychometrics features of the Snyder hope scale. Journal of Applied Psychology. 2011;5(19):7-23.

27- Farnia F, Zarei H, Baghshahi N. The Effectiveness of group hope herapy on happiness in hemodialysis patients. The J Urmia Nurs Midwifery Fac. 2016;14(6):543-50.

28- Poorgholami F, Abdollahifard S, Zamani M, Kargar Jahromi M, Badiyepeyma Jahromi Z. The Effect of Stress Management Training on Hope in Hemodialysis Patients. Glob J Health Sci. 2015;8(7):165-71. DOI: 10.5539/gjhs.v8n7p165 PMID: 26925895

29- Cha J, Yi M. The Influence of Cognitive Coping on Hope, Depression and Satisfaction with Life in Hemodialysis Patients. Korean J Adult Nurs. 2013;25(4):389. DOI: 10.7475/ kjan.2013.25.4.389

30- Cha J, Han D. Factors related to Hope and Relationships between Hope, Physical Symptoms, Depressive Mood and Quality of Life in Young Adult and Prime-aged Patients with Hemodialysis. J Korean Academy of Psychiatric \& Mental Health Nurs. 2014;23(4):250. DOI: 10.12934/jkpmhn.2014.23.4.250

31- Cho I-H, Suh S-R, Jang K-H. Effects of the MBSR Program on Stress Response, Psychosocial Adaptation and Health Related Quality of Life in Patients undergoing Hemodialysis. International Information Institute (Tokyo) Information. 2017;20(12):8589-96.

32- Soundy A, Benson J, Dawes H, Smith B, Collett J, Meaney A. Understanding hope in patients with Multiple Sclerosis. Physiotherapy. 2012;98(4):344-50. DOI: $10.1016 / \mathrm{j}$. physio.2011.05.003 PMID: 23122442

33- Camry Saman F. The Effectiveness of Teaching Spirituality Therapy Based on Positive Negative Approach on the Level of Life expectancy and Adolescent Satisfaction. Clinic Psychol Res Counsel. 2017;6(1):5-23.

34- Morasei F, Aghajani M. The Effect of counseling with spirituality approach on Hope in patients with chronic renal failure. Complement Med J faculty Nurs \& Midwif. 2014;4(2):776-86.

35- Bandura A, Locke EA. Negative self-efficacy and goal effects revisited. J Appl Psychol. 2003;88(1):87-99. DOI: 10.1037/00219010.88.1.87 PMID: 12675397

36- Betz N, Hackett G. Career Self-Efficacy Theory: Back to 
the Future. J Career Assessment. 2016;14(1):3-11. DOI: $10.1177 / 1069072705281347$

37- Orlandi Fde S, Pepino BG, Pavarini SC, Dos Santos DA, de Mendiondo MS. [The evaluation of the level of hope of elderly chronic kidney disease patients undergoing hemodialysis]. Rev Esc Enferm USP. 2012;46(4):900-5. DOI: 10.1590/s008062342012000400017 PMID: 23018400

38- Alberto J, Joyner B. Hope, optimism, and self-care among Better Breathers Support Group members with chronic obstructive pulmonary disease. Appl Nurs Res. 2008;21(4):212-7. DOI: 10.1016/j.apnr.2006.12.005 PMID: 18995163

39- Bluvol A, Ford-Gilboe M. Hope, health work and quality of life in families of stroke survivors. J Adv Nurs. 2004;48(4):322-32. DOI: 10.1111/j.1365-2648.2004.03004.x PMID: 15500526

40- Evangelista LS, Doering LV, Dracup K, Vassilakis ME, Kobashigawa J. Hope, mood states and quality of life in female heart transplant recipients. The Journal of Heart and Lung Transplantation. 2003;22(6):681-6. DOI: 10.1016/s10532498(02)00652-6
41- Khoshnazar T, Farmanbar R, Moghamnia M, Izadi Tameh A, Rostamnia L, Monfared A. Relevance self-efficacy with anxiety and depression among patients receiving hemodialysis referred to hemodialysis unit at educational-therapeutic center in Rasht. The Journal of Urmia Nursing and Midwifery Faculty. 2014;12(9):807.

42- Madadkar S, Basiri M. Effect of Relaxation Jacobson on quality of Life and self-efficacy in Patients Undergoing Hemodialysis. Complementary Medicine Journal of faculty of Nursing \& Midwifery. 2018;7(4):2090-9.

43- Pun PH, Dupre ME, Starks MA, Tyson C, Vellano K, Svetkey LP, et al. Outcomes for Hemodialysis Patients Given Cardiopulmonary Resuscitation for Cardiac Arrest at Outpatient Dialysis Clinics. J Am Soc Nephrol. 2019. DOI: 10.1681/ASN.2018090911 PMID: 30733235

44- Hatef M, Sharif Nia H, Boyle C, Shafipour V. The Validity and Reliability of the Exercise Self-Efficacy Scale in a Sample of Hemodialysis Patients. J Nurs Meas. 2018;26(3):566-78. DOI: 10.1891/1061-3749.26.3.566 PMID: 30593578 